\title{
Asthma education program for First Nations children: An exemplar of the Knowledge-to-Action Framework
}

\author{
Maureen L Douglas BA LLB1 ${ }^{1}$, Shawna L McGhan RN (CRE) MN1, Danielle Tougas², Nancy Fenton RD PhD³, \\ Christopher Sarin MD CCFP FRCPC ${ }^{4}$, Oxana Latycheva $\mathrm{PhD}^{5}, \mathrm{~A}$ Dean Befus $\mathrm{PhD}^{1}$
}

\begin{abstract}
ML Douglas, SL McGhan, D Tougas, et al. Asthma education program for First Nations children: An exemplar of the Knowledgeto-Action Framework. Can Respir J 2013;20(4):295-300.
\end{abstract}

BACKGROUND: The prevalence of asthma in Aboriginal children is $6 \%$ to $14 \%$. Gaps in knowledge regarding asthma and its management exist in First Nations (FN) communities, and culturally relevant education and resources are required. Studies have recommended that the children's asthma education program, the 'Roaring Adventures of Puff', be modified through partnership with FN communities to be culturally appropriate. OBJECTIVE: To adapt this knowledge tool and design an effective implementation process for FN knowledge users (children with asthma and care providers), guided by the Canadian Institutes of Health Research knowledge translation framework.

METHODS: The problem was identified, knowledge was identified/ reviewed/selected (literature review); knowledge was adapted to the local context (FN working and advisory groups); barriers to knowledge use were assessed (by knowledge users); and interventions were selected, tailored and implemented (modified curricula and the creation of a new activity book and web-based resources, and regional coordinators, asthma educator mentors and community teams were recruited).

RESULTS: Major outcomes were the adapted tools and blueprints for tailoring implementation. Additional outcomes were preliminary observations and outputs from the iterative processes, including information about local context and barriers. Specific additions were roles for community members supported by asthma educators (applying FN teaching models and addressing health care demands); relevant triggers (addressing knowledge gaps); and FN images and stories, themes of circle, sacred teachings, nature and family/elders (culture and addressing low reading levels).

CONCLUSION: The framework model provides a logical, valuable tool for adapting a knowledge tool and implementation process to new knowledge users. Future research should measure uptake, effect on health outcomes of FN asthma sufferers and sustainability.

Key Words: Asthma; Children; Culturally relevant; First Nations; Health education; Knowledge translation
Le programme d'éducation sur l'asthme pour les enfants des Premières nations : un exemple du processus des connaissances à la pratique

HISTORIQUE : La prévalence de l'asthme est de $6 \%$ à $14 \%$ chez les enfants autochtones. On constate des lacunes relatives à l'asthme et à sa prise en charge dans les communautés des Premières nations (PN), et un enseignement et des ressources adaptés à la culture s'imposent. Dans les études, on recommandait de modifier le programme d'éducation sur l'asthme à l'aide du livre Roaring Adventures of Puff pour l'adapter à la culture, grâce à un partenariat avec les communautés des PN.

OBJECTIF : Adapter cet outil et concevoir un processus de mise en œuvre simple pour les utilisateurs du savoir des PN (enfants asthmatiques et dispensateurs de soins), d'après le cadre de transfert du savoir des Instituts de recherche en santé du Canada.

MÉTHODOLOGIE : Les chercheurs ont ciblé le problème, déterminé, analysé et sélectionné les connaissances (analyse bibliographique), adapté le savoir au contexte (groupes de travail et groupes consultatifs des PN), évalué les obstacles à l'utilisation du savoir (par les utilisateurs du savoir) et sélectionné, adapté et mis en œuvre les interventions (modification du cursus et création d'un nouveau livre d'activités et de nouvelles ressources virtuelles, et recrutement de coordonnateurs régionaux, de mentors des éducateurs sur l'asthme et d'équipes communautaires).

RÉSULTATS : Les outils et les plans adaptés en vue de la mise en œuvre étaient les principaux résultats. Les observations et les commentaires préliminaires découlant des processus itératifs, y compris de l'information sur le contexte et les obstacles locaux, faisaient partie des résultats supplémentaires. Les ajouts précis étaient le rôle des membres de la communauté, soutenus par des éducateurs sur l'asthme (mise en application de modèles d'enseignement aux PN et réponse aux demandes de soins), les déclencheurs pertinents (corriger les lacunes) et les images et les histoires des PN, les thèmes du cercle, les enseignements sacrés, la nature et la famille et les Anciens (culture et prise en compte du faible niveau de lecture).

CONCLUSION : Le modèle fournit un outil logique et précieux pour adapter un outil du savoir et un processus de mise en œuvre à de nouveaux utilisateurs du savoir. Une prochaine recherche devrait mesurer l'utilisation, l'effet sur les issues de santé des membres de PN atteints d'asthme et la pérennité.

professionals for small groups of children in the school setting. RAP School has been tested in five populations resulting in positive outcomes: improved quality of life for children $(5,6)$ and parents $(7)$; better self-efficacy (6); fewer absences (6); fewer days of interrupted activity (6); fewer urgent health care visits (5-8); and improved parental home productivity (7). RAP-IT, a self-paced online course taking approximately $20 \mathrm{~h}$ to complete, has been pilot tested, and health professionals have positively evaluated its quality, features and applicability to practice (9).

Asthma is one of the most common chronic conditions of Canadian Aboriginal children, affecting between $6 \%$ and $14.6 \%$ of this population (10-12). Many factors impose a disproportionate burden of illness on Aboriginal children with asthma and their families (13). These include high smoking rates $(13,14)$ (70\% in First Nations [FN] youth [15]); and environmental factors $(10,13,14)$ such patient-doctor partnership. RAP School is hosted by health care

${ }^{1}$ Alberta Asthma Centre, University of Alberta, Edmonton; ${ }^{2}$ Health Sciences, Faculty of Medicine, University of Calgary, Calgary, Alberta;

${ }^{3}$ School of Public Health and Health Systems, Faculty of Applied Health Sciences, University of Waterloo, Waterloo, Ontario; ${ }^{4}$ First Nations

and Inuit Health, Health Canada, Alberta Branch; ${ }^{5}$ Asthma Society of Canada (current affiliation, Ontario Lung Association), Ontario.

Correspondence: Dr A Dean Befus, Director Alberta Asthma Centre, Room 557 HMRC, Department of Medicine, University of Alberta,

Edmonton, Alberta T6G 2S2. Telephone 780-492-5381, fax 780-492-6739, e-mail dean.befus@ualberta.ca 
as mold, smoking in homes and road dust contributing to asthma exacerbations $(10,16)$; and geographical, cultural and socioeconomic factors (11) limiting access to care (13). Uncontrolled asthma can also lead to other health concerns such as depression $(13,17)$.

Studies show gaps in asthma knowledge and resources for FN children with asthma living and attending school on reserve, and also for caregivers (18). Pilot studies using RAP School in FN communities suggested that it be modified to better address the needs of FN children with asthma $(18,19)$. The Knowledge-to-Action Framework (Framework) (20) was selected to adapt RAP School to address gaps. This model delineates two concepts: knowledge creation and action (action cycle). Although the model depicts ideal milestones, "in reality, the process is complex and dynamic, and the boundaries between these two concepts are fluid and permeable" (20).

Our objective was to apply the Framework (20) to implement an asthma education program in new knowledge users (eg, FN children with asthma and their caregivers). The current report focuses on the first four phases of the action cycle, namely: identify problem/ identify, review, select knowledge; adapt knowledge to local context; assess barriers to knowledge use; and select, tailor and implement interventions.

\section{METHODS}

\section{Introduction to collaborative processes and collaborators}

Several collaborative processes were designed to inform the adaptation of RAP. These processes (collaborative processes), the collaborating parties (collaborators), their roles and responsibilities, connection to Framework components and outcomes are shown in Table 1. These processes were nonlinear in operation and each contributed to more than one of the action cycle components. For example, workshop participants expanded understanding of the problem's scope and specifics; affirmed the selection of RAP as the knowledge tool; and provided insight to adapt the tool to the local context and to identify barriers and corresponding strategies to implement.

Phase 1: Identify problem/identify, review and select knowledge The first action cycle phase was substantially completed by partners of the Alberta Asthma Centre (Edmonton, Alberta) before the current project $(18,19)$; they assessed available resources and pilot-tested RAP in FN communities, which led to recommendations that it be adapted to improve its cultural appropriateness $(18,19,21)$.

\section{Phases 2 and 3: Adapt knowledge to local context and assess barriers}

To make the tool more likely to be directly relevant to and used by knowledge users, a nationally representative group (advisory group) was convened and a workshop (workshop) tasked with determining what relevance RAP had for FN children and communities, identify strengths and barriers and work through changes to the curricula and delivery model. To facilitate ongoing participation, a collaboration website (collaboration site) was established for all collaborators.

An electronic survey was e-mailed to 60 RAP instructors, health professionals and academics with expertise in asthma education, requesting participation if they had $\mathrm{FN}$ health experience. The survey sought recommendations about content and format of RAP School and RAP-IT, challenges to delivery and strategies to optimize participation and uptake.

The Asthma Society of Canada conducted surveys and interviews with 13 FN children with asthma and their caregivers about the activity book used with RAP School ('Fun Book').

\section{Phase 4: Tailor and implement the interventions}

Input gathered was used to tailor interventions. Provincial coordinators were recruited where there were pre-existing relationships with asthma educators and/or FN communities. Each coordinator invited FN reserve communities to implement RAP, facilitated RAP-IT and acted as an asthma education mentor. Communities were invited to form teams that consisted of health and lay members to obtain approvals, enrol in RAP-IT and host RAP School.

Select activities of RAP School were pilot tested at a 2.5-day camp for 19 FN children with asthma, allergies and eczema. After each activity, children were asked to answer two questions by marking individual 'bulls-eye' target surveys, namely: "Did you have fun at this activity?"; and "Will this game help your asthma?" After this pilot, the organizer was interviewed about RAP School and its delivery model.

RAP School was implemented in two remote FN community schools by a RAP educator who travelled from an urban centre. RAP-IT was hosted over nine months for a class of 40 individuals comprised of enrolled team members $(n=16)$, coordinators, project partners and others involved in FN health. A telephone survey of enrolled team members solicited information regarding demographics, learning preferences and satisfaction (22).

\section{RESULTS}

Outcomes included the adapted RAP knowledge tools, identified barriers and facilitators to implementation, and tailored implementation strategies. Processes used to achieve these outcomes and involved groups along with their roles and responsibilities are described in Table 1.

\section{Phase 1: Identify the problem/identify, review and select knowledge}

Collaborators identified gaps in knowledge relating to asthma and asthma management skills. They described the frequency of inhaler use and asthma exacerbations requiring emergency care. They discussed fears of 'asthma attacks', feelings of isolation and resulting withdrawal from physical and cultural activities. They identified social and health issues that they believed affected the community's ability to respond.

Collaborators reviewed the tools and knowledge, and endorsed RAP School as a valuable and appropriate tool to adapt for FN children. They confirmed the school setting where children are a "captive audience". They emphasized that RAP School contained many important concepts and did not require significant changes to be engaging and have impact on FN children.

\section{Phase 2: Adapt knowledge to local context}

Earlier assessments $(18,19)$ suggested that materials should support visual learning, use storytelling and anecdotes from FN families and involve family members. Collaborators expanded these recommendations to make RAP reflect/include FN peoples and address asthma knowledge gaps, learning preferences and barriers to uptake. Collaborators emphasized to avoid generalizing characteristics of any one tribe/nation to all FN communities and to focus on nature, wellness and rural themes including relevant community triggers (road dust, wood fire smoke, viruses, tobacco smoke, mold and overcrowding) and early identification of symptoms, and feelings of isolation and prevention. Themes that emerged from the children's interviews about the activity book were: reduce the amount of text; keep the drawing and colouring activities; use colour; ensure the activities are fun and exciting; add more pictures; and ensure that information about medications, device technique and airways is easy to understand.

Corresponding modifications were also made to RAP-IT. It was condensed from 12 modules to five, made less text-based by adding avatar narrators, screen casts and video demonstrations, contextualized to FN by adding stories/photos/art from FN children, their caregivers, community members and health providers and made more interactive by hosting "Sharing Circle" forums, teleconferences and webinars. Hands-on technological support (including teleconferences and screen casts about RAP-IT navigation) and mentorship from asthma educators were provided.

Specific adaptations to RAP School and the Fun Book included incorporating more tactile and outdoor activities; more humour; the imagery of the circle; the seven sacred teachings; and inclusion of elders, family members and the community. Role-playing activities 
TABLE 1

Knowledge-to-Action process: Processes used, groups, and roles and responsibilities

\begin{tabular}{|c|c|c|}
\hline Process/collaborators & Roles and responsibilities & Outputs \\
\hline $\begin{array}{l}\text { Advisory group: } \\
\text { Months } 1 \text { to } 15 \\
\mathrm{n}=10 ; \text { elders, an allergist, certified } \\
\text { asthma educators, RAP Instructors } \\
\text { with experience in FN communities, } \\
\text { Assembly of FN health policy } \\
\text { analyst, FN health advisor, } \\
\text { academics with interest in asthma } \\
\text { and FN health; } \\
\text { Communicated via phone meetings, } \\
\text { e-mail and collaboration website }\end{array}$ & $\begin{array}{l}\text { Input into: } \\
\text { - Project design and processes; } \\
\text { - Identification of potential partners and } \\
\text { implementation sites; } \\
\text { - Adaptation of RAP, RAP-IT } \\
\text {-Implementation and evaluation } \\
\text { methods }\end{array}$ & $\begin{array}{l}\text { Identified problem/reviewed and selected knowledge: confirmed asthma as a } \\
\text { problem, lack of awareness and culturally relevant tools; provided context in } \\
\text { FN communities; confirmed value of tool and suitability to FN } \\
\text { Adapted knowledge tool: provided asthma expertise, gaps in knowledge (eg, } \\
\text { medication differentiation and technique), available resources, lessons from } \\
\text { previous delivery, gaps in FN content } \\
\text { Assessed barriers: outlined barriers to RAP and health care access at } \\
\text { individual/school/health centre/community level } \\
\text { Tailored intervention: provided advice about criteria and candidates for pilot site } \\
\text { communities, ethics and approval processes, recruitment and retention } \\
\text { strategies }\end{array}$ \\
\hline $\begin{array}{l}\text { Workshop } \\
\text { Month } 2 \\
n=12 ; \text { RAP-IT graduates with FN } \\
\text { exposure, FN elders, senior } \\
\text { representative from Assembly of } \\
\text { FN, asthma coordinators in FN } \\
\text { communities; } \\
\text { PHSAP and Ontario Lung } \\
\text { Association; } \\
\text { Academics (with expertise in child } \\
\text { health, asthma education, asthma } \\
\text { in schools, community develop- } \\
\text { ment), Winnipeg Children's Asthma } \\
\text { Education Centre, RAP participants } \\
\text { from Ontario FN communities, } \\
\text { AllerGen researchers }\end{array}$ & $\begin{array}{l}\text { Participate in one-day session involving: } \\
\text { - Presentation of previous projects } \\
\text { and RAP features; } \\
\text { - Discussion of problem, local context, } \\
\text { barriers, implementation process; } \\
\text { - Input on specific changes to RAP, Fun } \\
\text { Book, RAP-IT and delivery model }\end{array}$ & $\begin{array}{l}\text { Identified problem/reviewed and selected knowledge: identified concerns about } \\
\text { proper diagnosis, misconceptions about asthma, triggers and medications, } \\
\text { high rate of tobacco use, family context (competing stresses, size of family, } \\
\text { variety of caregivers, socioeconomic factors), access to care (remoteness, } \\
\text { transportation, child care, history of negative health care experiences), low } \\
\text { reading levels } \\
\text { Adapted knowledge tool: specific adaptations to activities (triggers; medication } \\
\text { technique, themes of nature, family, etc) } \\
\text { Assessed barriers: health staff demands and turnover; wariness of 'research' } \\
\text { Tailored intervention: suggested lay member as facilitator; to adapt RAP-IT for } \\
\text { team approach and for lay members; suggested community-based teams } \\
\text { implement; advice about whether intervention is "research", novel evaluation } \\
\text { methods, how to obtain approvals, appropriate gifts }\end{array}$ \\
\hline $\begin{array}{l}\text { Survey } \\
\text { Months } 2 \text { to } 3 \\
\text { n=15; RAP School instructors, health } \\
\text { professionals (nurses }=80 \% \text { ), and } \\
\text { academics with expertise in asthma } \\
\text { and FN experience }\end{array}$ & $\begin{array}{l}\text { On-line survey; } 42 \text { questions regarding: } \\
\text { - Demographics; } \\
\text { - Experience; } \\
\text { - Content and format of RAP School } \\
\text { and RAP-IT; } \\
\text { - Challenges and barriers to delivery; } \\
\text { - Strategies to optimize participation/ } \\
\text { uptake }\end{array}$ & $\begin{array}{l}\text { Identified problem/reviewed and selected knowledge: endorsed RAP School as } \\
\text { a valuable tool } \\
\text { Adapted knowledge tool: recommended to keep it "visual," hands-on, active, } \\
\text { interactive, creative and to employ encouragement/rewards; to make the } \\
\text { content more relevant to FN children (eg, including traditional drumming in } \\
\text { RAP songs, a medicine wheel, traditional healing, storytelling, community } \\
\text { involvement, respect for elders, self-respect, animals and role models) } \\
\text { Assessed barriers: school ideal setting; limitations to delivery may include: lack } \\
\text { of family involvement, "schools already have so many issues to deal with", } \\
\text { kids go home for lunch, getting school approval and kids must give up recess } \\
\text { time }\end{array}$ \\
\hline $\begin{array}{l}\text { Collaboration website } \\
\text { Months } 3 \text { to } 15 \\
\text { n=79; Advisory group, workshop } \\
\text { participants, regional coordinators, } \\
\text { community-based teams (including } \\
\text { potential teams) and other partners } \\
\text { including FN Inuit Health, Alberta } \\
\text { Region }\end{array}$ & $\begin{array}{l}\text { Online; voluntary participation; } \\
\text { Facilitated collaboration: } \\
\text { - } 11 \text { discussion forums; } \\
\text { - Posted project processes, curriculum, } \\
\text { templates, new activities, evaluation, } \\
\text { training, activity book, toolkits; } \\
\text { - Announcements; } \\
\text { - Host webinars }\end{array}$ & $\begin{array}{l}\text { Adapted knowledge tool: discussed themes from Workshop, survey and other } \\
\text { collaborative activities; input on RAP-IT curriculum, specific RAP School } \\
\text { activities; discussion of use of performance arts, pictures/video, Smartboard/ } \\
\text { computer applications, physical play, music, nature, etc; posted adapted } \\
\text { curricula; ongoing feedback on the art, layout and drafts of the new activity } \\
\text { book } \\
\text { Tailored intervention: announced webinars, teleconferences and training } \\
\text { opportunities, discussion of progress, templates for approval and community } \\
\text { engagement; ongoing input on the approach and evaluation }\end{array}$ \\
\hline $\begin{array}{l}\text { Interviews of FN children and } \\
\text { caregivers (children's Interviews) } \\
\text { Months } 3 \text { to } 4 \\
n=13 ; \text { FN children with asthma and } \\
\text { caregivers }\end{array}$ & $\begin{array}{l}\text { Assessed original activity book of } \\
\text { RAP School for: } \\
\text { - Content; } \\
\text { - Format; } \\
\text { - Suggestions }\end{array}$ & $\begin{array}{l}\text { Adapted knowledge tool: recommended reducing the amount of text; keeping } \\
\text { the drawing and colouring activities; using colour; ensuring that activities are } \\
\text { fun and exciting; adding more pictures; ensuring that medications, device and } \\
\text { airways information is easy to understand }\end{array}$ \\
\hline $\begin{array}{l}\text { Regional coordinators and certified } \\
\text { asthma educators mentors } \\
\text { Months } 3 \text { to } 15 \\
\mathrm{n}=4 \text {; had pre-existing relationships } \\
\text { with FN communities }\end{array}$ & $\begin{array}{l}\text { Provided mentorship by: } \\
\text { - Inviting FN reserve communities to } \\
\text { implement RAP; } \\
\text { - Liaised with community; } \\
\text { - Facilitated RAP-IT; } \\
\text { - Supported and consulted on asthma } \\
\text { education; } \\
\text { - Communicated on the Collaboration } \\
\text { website }\end{array}$ & $\begin{array}{l}\text { Assessed barriers/selected and tailored intervention: provided information } \\
\text { about specific facilitators (identifying asthma champions) and barriers } \\
\text { (socioeconomic, weather, suicides, nonresponsive school administrators); } \\
\text { provided knowledge about asthma and teaching skills tailored to individual } \\
\text { needs of community;contributed to webinars when team members expressed } \\
\text { need for interactive curriculum; built and sustained relationships with FN } \\
\text { communities }\end{array}$ \\
\hline $\begin{array}{l}\text { Community-based teams } \\
\text { Months } 3 \text { to } 15 \\
n=8 \text {; health and lay members }\end{array}$ & $\begin{array}{l}\text { Communities invited to: } \\
\text { - Identify team members; } \\
\text { - Obtain/guide necessary approvals; } \\
\text { - Enrol in RAP-IT; } \\
\text { - Host RAP School }\end{array}$ & $\begin{array}{l}\text { Tailored intervention: Community teams reinforced key messages and sustained } \\
\text { asthma education, gathered community input on children's perspectives and } \\
\text { asthma needs, delivered RAP School and supported appropriate access to } \\
\text { health care }\end{array}$ \\
\hline
\end{tabular}

FN First Nations; PHSAP Public Health School; Asthma Project; RAP-IT 'Roaring Adventures of Puff' instructor training; RAP School 'Roaring Adventures of Puff' children asthma education program (original) 
were developed with input from family members and local nurses to include social and family situations. The wolf was recommended as a culturally relevant mascot based on its symbolism as a teacher and member of a larger community, and for its capacity to howl, which was symbolic of strong lungs. A Dené artist was commissioned to create relevant images in the new activity book, The Legend of Tahnee the Wolf: My Asthma Journey (Tahnee Book) (4). Content was added to assist children to identify and address triggers relevant in FN communities. Adaptations emphasized a holistic approach to health, featuring themes of physical activity, prevention and wellness.

\section{Phase 3: Assess barriers to knowledge use}

Collaborators identified several contextual barriers to knowledge use including individual health (comorbidities), the health system (lack of diagnosis, funding levels, competing staff demands, strain of acute care), access to care (remoteness, child care, negative health care experiences), capacity of family/schools/community to respond (stresses, variety of caregivers, socioeconomic factors), a lack of asthma awareness and low reading levels. They described the tension among asthma prevention, the cultural significance of tobacco and wariness about taking prescription medications. The collaborators focused on immediate barriers to knowledge use relating to reading level, participation, health care issues affecting implementation, approvals and community engagement.

\section{Phase 4: Select, tailor, implement interventions}

The existing RAP already promoted adaptation to group needs. For example, the number and length of sessions and types of activities of RAP School were chosen after assessment of the individuals, groups and school. However, modifications to new RAP increased the selection and tailoring options. First, collaborators suggested that due to competing demands, staff turnover and technology issues, it would not be feasible in some communities for health professionals to complete RAP-IT and deliver RAP School. As a result, the refined delivery model featured teams comprised of medical and lay members, a hybrid of online and video conferencing training, and mentoring by certified asthma educators (with flexibility to respond to needs in individual communities). Second, suggestions were added to engage communities, strengthen relationships, promote awareness and build capacity through FN community events.

The pilot in the camp setting facilitated further tailoring of the intervention. Modifications were made to the delivery model including flexibility in group size and ages of children, a greater ratio of adults to children, rotation of 'breakout' activities for children, and active roles for peer mentors and community members. In the target surveys, children responded favourably to the new and modified activities: 45 of 48 responses rated the 'fun factor' as $4 / 5$ or $5 / 5 ; 39$ of 43 rated the impact as $4 / 5$ or $5 / 5$.

Of 10 community sites invited to implement the intervention, eight agreed to participate. Seventeen team members enrolled in RAP-IT. However, despite ongoing communication and a nine-month window to complete, only one team member completed the course. RAP was implemented in two FN communities by an experienced RAP educator; community members were invited but were not involved in education. Delivery and activities were tailored to accommodate impassable roads, challenging school schedules, community events, children's preferences and the educator's observations of which approaches had impact.

Unfortunately, funding and timelines (15 months) for adaptation and implementation were limited and could not be substantially extended. This significantly impacted the implementation phase, which necessarily followed adapting the tool and assessing barriers. Also, a number of the identified barriers delayed community asthma activities such as lack of asthma awareness, competing demands on health services, suicides, reticence to participate in research and approval protocols. Additional time may have enhanced the ability to foster relationships, respond to local needs and preferences, and build the case for asthma education as a priority, which may have led to implementation in more communities.

\section{Preliminary observations}

Although evaluation of this project is at the design stage, some preliminary observations are available. As with the knowledge tools and intervention, the evaluation plan has continued to evolve through the development and implementation stages. Because community members expressed fatigue with surveys and interviews, less formal methods have and will be used to collect qualitative data regarding the impact of RAP, along with ongoing barriers/facilitators data. Methods include an art evaluation activity, a survey and qualitative feedback from the RAP educator. Children who completed RAP School have been asked to use a creative medium to answer the following question: "Now that you have completed RAP School, how has (or, how will) it change your life with asthma?" This ongoing activity was designed in collaboration with researchers who used children's artwork to explore the child's perspectives about anaphylaxis (23). Current qualitative observations include a letter from a child expressing how much she appreciates the RAP educator's time and effort, and an observation from a parent that the classes have "really helped her child understand how to better manage her asthma".

Ten of 11 survey respondents believed that RAP School would help kids with asthma in their community and expressed interest in continued participation, and eight would recommend it to other FN communities. Given the low observed rate of completion of RAP-IT among FN team members, information about barriers to participation (collected after implementation) was particularly important. Among 14 respondents (of this portion of the survey), frequently cited barriers were: difficulties related to the work environment $(n=14)$; lack of work time reserved for the course $(n=4)$; the need to replace other staff in addition to completing one's own work $(n=3)$; and lack of time because the program was not part of the respondent's job description $(n=3)$. Other barriers included technical issues $(n=7)$, dislike of course format $(n=5)$, poor timing $(n=3)$, personal demands $(n=2)$ and being too busy $(n=10)$.

\section{DISCUSSION}

Application of the first four components of the action cycle resulted in three major outputs, namely, the modified curricula (including the Tahnee Book), modified delivery process and a model for collaborative adaptation that could be used in future similar work. Preliminary feedback about RAP School and the Tahnee Book was favourable, but uptake by FN team members has been suboptimal to date. Formal evaluation will be required to determine the success of this approach in bridging identified gaps between asthma guidelines and the needs of FN children for asthma education.

In applying the Framework, we gathered insight that will assist others implementing similar health programs in FN communities and in ensuring an integral role for knowledge users within the implementation process. Collaborators described the complexity of the problem, described its effects and actively participated in adaptation of the knowledge tools and assessment of the barriers. A novel feature of the new RAP is that lay community members assumed the role of instructors and were mentored (via videoconferencing, telephone or e-mail) by certified asthma educators. Similarly, using the school setting reduced barriers related to health service access, attendance and child engagement. Community 'asthma champions' learned about asthma and linked families to appropriate health service practitioners and resources. Active involvement from community members in an effort to enhance child participation included elders and community members involved in planning and facilitating educational and cultural activities and acting as peer mentors. A further strength was the flexibility built into the RAP School program (assessment tools and choices of activities, settings, session length, etc), which streamlined its adaptation to particular user groups. Overall, we believe that our collaborative development approach with active involvement of community members from the design stage increases the likelihood of sustained knowledge use.

It is critical to allocate sufficient time and resources to fully apply the phases of the Framework. Significant time is required to assess 
barriers and to tailor interventions. These phases require establishing and maintaining meaningful relationships in the community. Participation was optimal where the project team and/or coordinators had previous relationships with FN communities. The 15-month timeframe was insufficient for proper relationship building, face-to-face meetings, recruitment, adaptation and approval processes, which are part of implementation.

Fostering strong relationships, communication and transparency is essential. A participatory approach contributes to the general purpose of RAP and other health programs - building awareness, capacity and champions - and is consistent with the Tri-Council Policy Statement (24) and Assembly of First Nations' Guidelines (25). Communities advised that they were impeded by staff shortages, high turnover, competing demands and priorities. Although many confirmed that asthma and lung health were significant issues, and expressed enthusiasm about the project, there were significant fluctuations in participation. Considerable personal contact was required to maintain engagement. We hypothesize that uptake would improve with additional time to explore communities' priorities, apply appropriate protocol (including community ethics), build on community strengths and existing services and, where possible, address community barriers to engagement.

Presently, two FN communities continue implementation of RAP School. Community ethics approval is pending for the art evaluation activity and child interviews. RAP-IT remains open to team members, as well as newly enrolled FN communities and FN and Inuit Health Branch staff responsible for nursing, chronic disease and education. The Tahnee Book has been disseminated to FN communities, requesting Lung Associations and the Asthma Society of Canada. RAP School continues to be available online (4) and dissemination continues provincially and nationally through meetings with health administrators and FN communities.

\section{CONCLUSION}

The Framework model provides a logical and valuable approach for adapting a knowledge tool and implementation process to new knowledge users. Preliminary feedback suggests that RAP is useful and valuable to FN knowledge users. Applying the remaining Framework components will likely lead to uptake and sustainability of the knowledge, impact skills and behaviours and, ultimately, result in positive health outcomes.

AUTHORS' CONTRIBUTIONS: MD, SM, ADB, DT, OL and NF contributed to the conception and design of the project and to the analysis and interpretation of data. OL co-organized the Advisory Group and Workshop, and designed, implemented and provided data from the Children's Interviews. NF contributed to the design of the art activity, submission to the community health ethics board and participated as a collaborator. DT was a summer student who supported the design and implementation of the RAP-IT survey and analysis. CS supported community connections, provided advice on implementation and connected the project team with community-based health providers. MD, SM, and ADB drafted the paper. All authors were involved in critically revising the manuscript.

ACKNOWLEDGEMENTS: A portion of this work was funded by First Nations and Inuit Health, Health Canada, Alberta Branch. The work and opinions herein are not those of Health Canada. AllerGen NCE Inc. also contributed funding and support. The Alberta Asthma Centre gratefully acknowledges the considerable contribution of its partners: the Asthma Society of Canada; Elders, First Nations community members and kids with asthma; Children's Asthma Education Centre, the Children's Hospital of Winnipeg (Dr Allan Becker, Lesley Stewart, Jo-Anne St-Vincent and Bev Kulbaba); the Public Health School Asthma Project (KC Rautiainen); Ontario Lung Association (Ana MacPherson); Ambris Ford; JoAnna Gillespie; the Advisory Group; Workshop participants; Assembly of First Nations (Dr Diego Garcia); The Social Support Research Network (Dr. Miriam Stewart, Sharon Anderson, Roxanne Blood); The Lung Association of Alberta and NWT; COPD and Asthma Network of Alberta. The authors thank Carla Gilday for making The Legend of Tahnee, The Wolf: My Asthma Journey such a masterpiece.
ETHICS APPROVALS: Each grant that funded this project was reviewed by the University of Alberta Research Ethics Board and determined to be program development and evaluation, and not requiring ethics approval. The individual community members, who were invited to participate, were advised that neither they nor their community would be identified in publications of the results. The art contest activity was approved by the University of Waterloo, Office of Research Ethics Board. The organizers of the pilot obtained ethics approval from the University of Alberta Research Ethics Board and consents for the children to participate in the target surveys under a separate project.

\section{REFERENCES}

1. Global Strategy for Asthma Management and Prevention: Updated 2012. GINA Executive Committee. <http://ginasthma.org/local/ uploads/files/GINA_Report_2012Feb13.pdf> (Accessed April 13, 2013).

2. Lougheed MD, Lemiere C, Dell SD et al. Canadian Thoracic Society Asthma Management Continuum - 2010 consensus Summary for children six years of age and over, and adults. Can Respir J 2010;17:15-24.

3. McGhan SL, Wells HM, Befus AD. The "Roaring Adventures of Puff": A childhood asthma education program. J Pediatr Health Care 1998;12:191-5.

4. First Nations and Asthma. Alberta Asthma Centre, University of Alberta. < www.asthmacentre.ualberta.ca/en/Health $\% 20$ Innovations/First\%20Nations\%20and\%20Asthma.aspx> (Accessed January 5, 2013).

5. McGhan S, Wong E, Sharpe H et al. A children's asthma education program: Roaring Adventures of Puff (RAP), improves quality of life. Can Respir J 2010;17:67-73.

6. Cicutto L, Murphy S, Coutts D, et al. Breaking the access barrier: Evaluating an asthma center's efforts to provide education to children with asthma in schools. Chest 2005;128:1928-35.

7. Stewart, LJ, Gillespie, CA, Filuk, SE et al. The "Roaring Adventures of Puff" (RAP) - a school based asthma education program for children with asthma. Canadian Network for Respiratory Care and Education (ASED 10). Gatineau, November 10 to 12, 2011 (Abst).

8. McGhan SL, Wong E, Jhangri GS et al. Evaluation of an education program for elementary school children with asthma. J Asthma 2003;40:523-33.

9. McGhan SL, Cicutto L, Stewart M, et al. Knowledge translation of childhood asthma education for healthcare professionals. Canadian Network for Asthma Care Conference (ASED 10). Gatineau, November 10 to 12, 2011. (Abst)

10. Gao Z, Rowe BH, Majaesic C, O'Hara C, Senthilselvan A. Prevalence of asthma and risk factors for asthma-like symptoms in Aboriginal and non-Aboriginal children in the northern territories of Canada. Can Respir J 2008;15:139-45.

11. Crighton EJ, Wilson K, Senecal S. The relationship between socioeconomic and geographic factors and asthma among Canada's Aboriginal populations. Int J Circumpolar Health 2010;69:138-50.

12. MacMillan HL, Jamieson E, Walsh C, Boyle M, Crawford A, MacMillan A. The health of Canada's Aboriginal children: Results from the First Nations and Inuit Regional Health Survey. Int J Circumpolar Health 2010;69:158-67.

13. Loppie C, Wien F. Health Inequalities and Social Determinants of Aboriginal Peoples' Health. Prince George, BC: National Collaborating Centre for Aboriginal Health; 2009.

14. Chang H-J, Beach J, Senthilselvan A. Prevalence and risk factors of asthma in off-reserve Aboriginal children and adults in Canada. Can Respir J 2012;19:e68-e74.

15. Public Health Agency of Canada. Life and Breath: Respiratory Disease in Canada, 2007. Ottawa: Ministry of Health, 2007.

16. Garner R, Kohen D. Changes in the prevalence of asthma among Canadian children. Health Rep 2008;19:45-50.

17. Watson R, Castleden H, Masuda J, King M, Stewart M. Identifying gaps in asthma education, health promotion, and social support for Mi'kmaq families in Unama'ki (Cape Breton), Nova Scotia, Canada. Prev Chronic Dis 2012;9:E139.

18. Latycheva O, Hampson C, Greenwald M, Panetta S, Chera, R. A shared voice: Engaging First Nations and Inuit communities in the development of culturally appropriate asthma and allergy education materials and resources for youth and their families. Allerg Asthma Clin Immunol 2010;6:P32. (Abst) 
19. Growing healthy children and youth: Increasing awareness of childhood asthma prevalence and improving collaboration within the community. Ontario Lung Association. <www.on.lung.ca/ document.doc?id=555> (Accessed January 10, 2013).

20. Graham ID, Logan J, Harrison MB, et al. Lost in knowledge translation: Time for a map? J Contin Educ Health Prof 2006;26:13-24.

21. Fenton N, Elliott SJ, Vine MM, et al. Assessing needs: Asthma in First Nations and Inuit communities in Canada. Pimatisiwin 2012;10:71-81.

22. Graham ID, Logan J. Innovations in knowledge transfer and continuity of care. Can J Nurs Res 2004;36:89-103.

23. Fenton NE, Elliott SJ, Cicutto L, Clarke AE, Harada L, McPhee E. Illustrating risk: Anaphylaxis through the eyes of the food-allergic child. Risk Anal 2011;31:171-83.
24. Canadian Institutes of Health Research, Natural Sciences and Engineering Research Council of Canada, and Social Sciences and Humanities Research Council of Canada, Tri-Council Policy Statement: Ethical Conduct for Research Involving Humans. Government of Canada. <www.pre.ethics.gc.ca/pdf/eng/tcps2/ TCPS_2_FINAL_Web.pdf> (Accessed January 9, 2013).

25. Research Ethics Protocols and Guidelines. First Nations Environmental Health Network Assembly of First Nations. $<$ www.fnehin.ca/site.php/research_guidelines/> (Accessed January 9, 2013). 


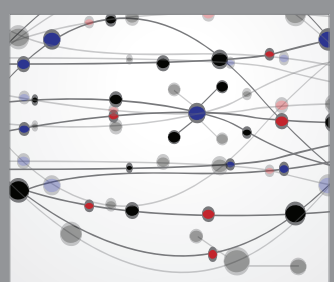

The Scientific World Journal
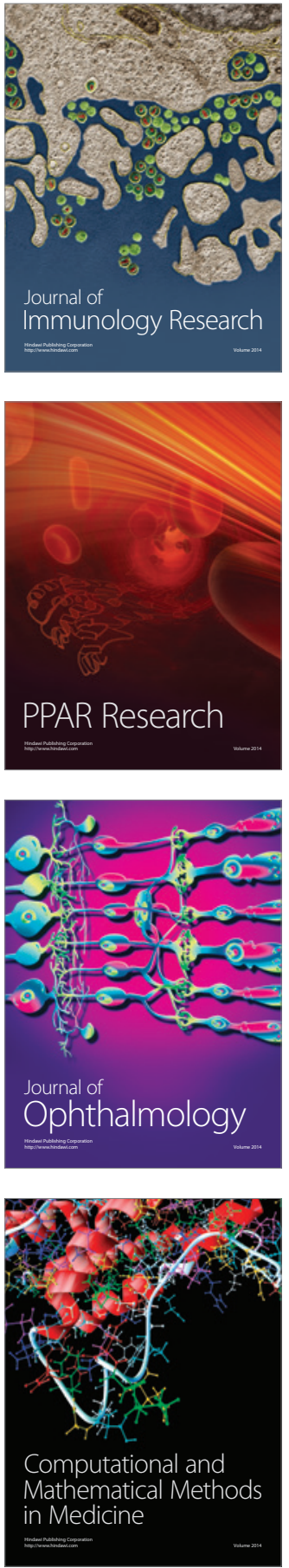

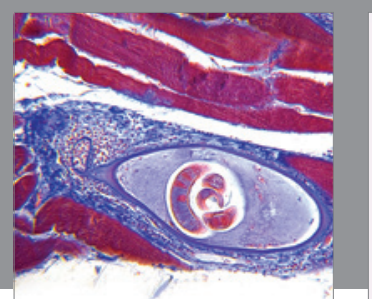

Gastroenterology Research and Practice

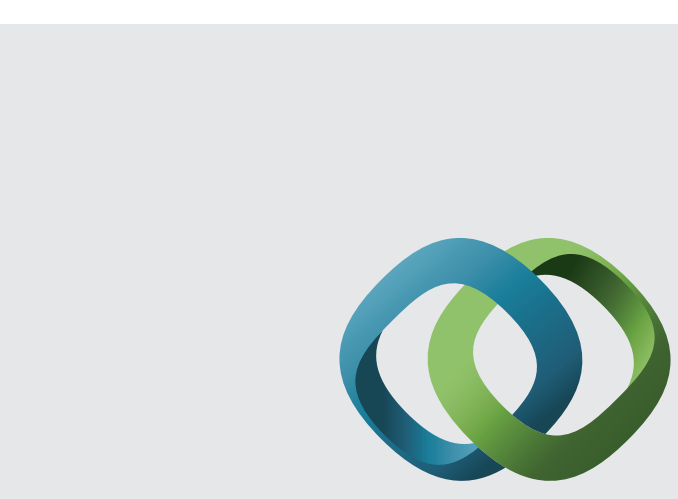

\section{Hindawi}

Submit your manuscripts at

http://www.hindawi.com
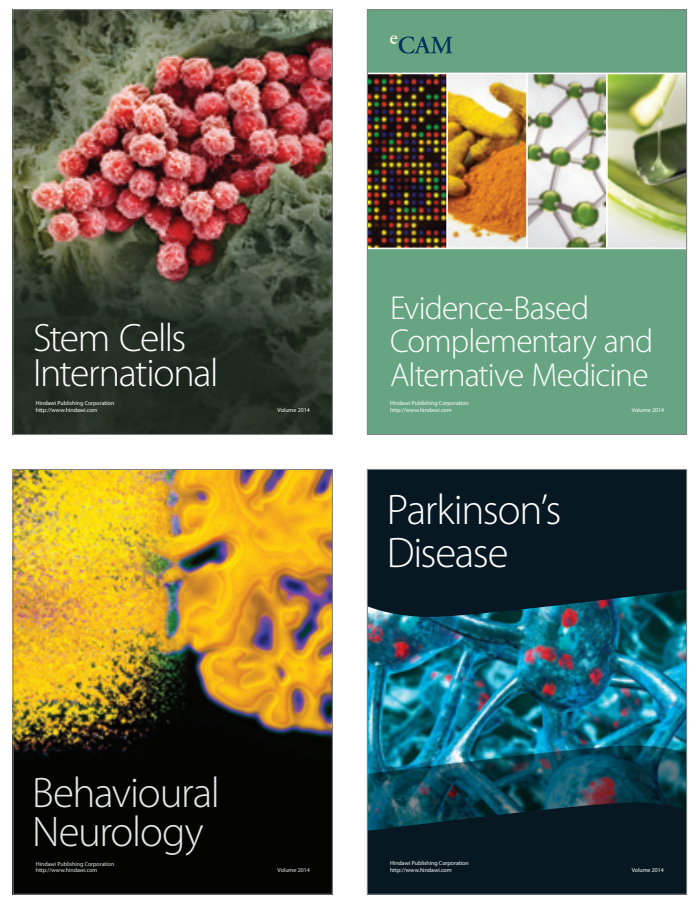
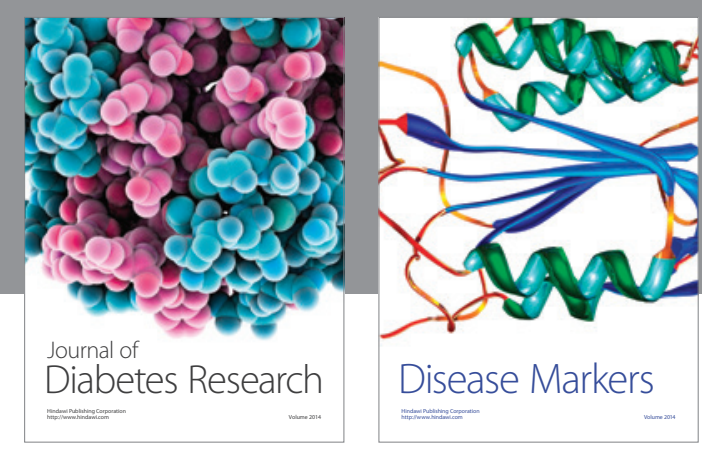

Disease Markers
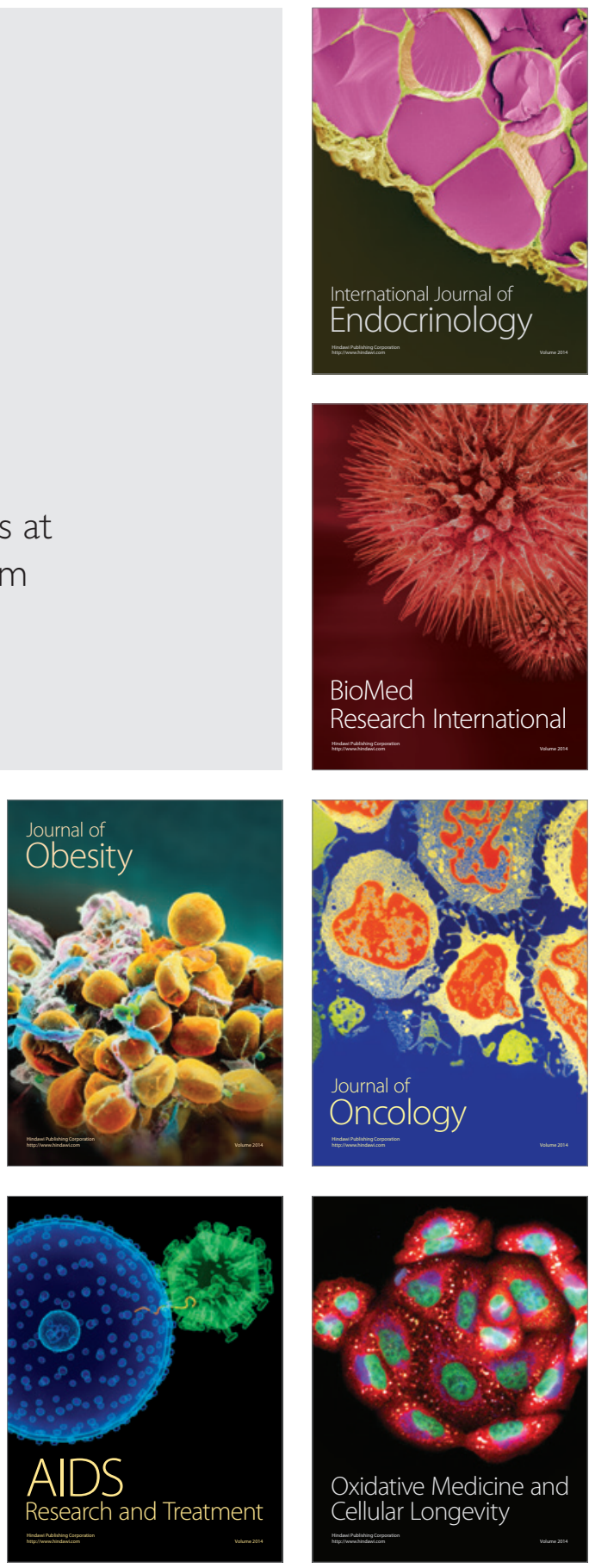